\title{
Effects of Asphyxia on Lung Fluid Balance in Baby Lambs
}

\author{
Thomas N. Hansen, Thomas A. Hazinski, \\ and Richard D. Bland \\ Cardiovascular Research Institute and Department of Pediatrics, \\ University of California, San Francisco, California 94143; \\ Department of Pediatrics, Baylor College of Medicine, Houston, \\ Texas 77030; and Department of Pediatrics, Northwestern \\ University School of Medicine, Chicago, Illinois 60614
}

bstract. The purpose of this study was to assess the effects of combined hypoxia and hypercapnia and of severe asphyxia on lung water balance and protein transport in newborn lambs. We studied ten 2-4-wk-old anesthetized lambs which were mechanically ventilated first with air for $2-3 \mathrm{~h}$, then with $10-12 \%$ oxygen in nitrogen for $2-4 \mathrm{~h}$, and then with $10-12 \%$ oxygen and $10-12 \%$ carbon dioxide in nitrogen for $2-4 \mathrm{~h}$. Next we stopped their breathing for 1-2 min to produce severe asphyxia, after which we followed their recovery in air for 2-4 h. In 5 of the 10 lambs we intravenously injected radioactive albumin and measured its turnover time between plasma and lymph during the baseline period and after recovery from asphyxia.

During alveolar hypoxia alone, mean pulmonary arterial pressure increased $60 \%$ and lung lymph flow increased $74 \%$, whereas lymph protein concentration decreased from $3.47 \pm 0.13$ to $2.83 \pm 0.15 \mathrm{~g} / \mathrm{dl}$. Cardiac output, left atrial pressure, and plasma protein concentration did not change. When carbon dioxide was added to the inspired gas mixture, pulmonary arterial pressure increased $22 \%$, cardiac output increased $13 \%$, lung lymph flow increased $33 \%$, and lymph protein concentration decreased from $2.83 \pm 0.15$ to $2.41 \pm 0.13 \mathrm{~g} / \mathrm{dl}$. Left atrial pressure and plasma protein concentration did not change. After 60-90 s of induced asphyxia, vascular pressures and lung lymph flow rapidly returned to values the same as those obtained during the baseline period. The turnover

R. D. Bland did part of this work during his tenure as an Established Investigator of the American Heart Association.

Address reprint requests to Dr. Hansen, Baylor College of Medicine. Received for publication 14 November 1983 and in revised form 16 February 1984.

J. Clin. Invest.

(C) The American Society for Clinical Investigation, Inc.

0021-9738/84/08/0370/07 \$1.00

Volume 74, August 1984, 370-376 time for radioactive albumin between plasma and lymph was the same between the baseline and recovery periods ( $185 \pm 16$ vs. $179 \pm 12 \mathrm{~min}$ ). The ratio of albumin to globulin in lymph relative to the same ratio in plasma did not change during any phase of these experiments. Five lambs killed after recovery from asphyxia had significantly less blood and extravascular water in their lungs than control lambs had. We conclude that in the newborn lamb both alveolar hypoxia and alveolar hypoxia with hypercapnia increase lung lymph flow by increasing filtration pressure in the microcirculation, but neither hypoxia with hypercapnia nor brief severe asphyxia alters the protein permeability of the pulmonary microcirculation.

\section{Introduction}

Respiratory failure from pulmonary edema often follows severe asphyxia. Some investigators have attributed this lung fluid imbalance to elevated pulmonary venous pressures associated with heart failure (1-5); others have suggested that endothelial cell injury is the source of the edema (6-8). Adamson and co-workers (3) produced severe asphyxia in fetal lambs by occluding the umbilical circulation. They found that left atrial pressure and lung lymph flow both increased but that microvascular permeability to protein was not affected. In contrast, O'Brodovich and co-workers (8) found that the combination of alveolar hypoxia and hypercapnia increased lung lymph flow without altering left atrial pressure in year-old sheep. They attributed the increase in lymph flow to an increase in protein permeability of the pulmonary microcirculation.

The purpose of this study was to assess the effects of combined hypoxia and hypercapnia and of severe asphyxia on lung water balance and protein transport in newborn lambs. We studied ten 2-4-wk-old anesthetized lambs which were mechanically ventilated first with air for $2-3 \mathrm{~h}$, then with $10-12 \%$ oxygen in nitrogen for 2-4 $\mathrm{h}$, and then with $10-12 \%$ oxygen and $10-12 \%$ carbon dioxide in nitrogen for 2-4 h. Next we stopped their breathing for 1-2 min to produce severe asphyxia, after which we followed their recovery for 2-4 h. 
We found that alveolar hypoxia and alveolar hypoxia combined with hypercapnia increased lung lymph flow by increasing filtration pressure in the pulmonary microcirculation. Neither hypoxia with hypercapnia nor severe asphyxia affected the permeability of the pulmonary microvascular bed to protein.

\section{Methods}

Surgical preparation. Surgical preparation of the lambs is described in detail elsewhere $(9,10)$. Each lamb had two operations, the first within $2 \mathrm{~d}$ of birth and the second 7-10 d later. We used halothane and nitrous oxide anesthesia through a piston type respirator during both operations. Before and after surgery the lambs remained with their mothers for feeding and warmth.

In the first operation, we inserted polyvinyl catheters into a peripheral artery and vein through an incision in the left leg and advanced the catheters until their tips were in the descending aorta and inferior vena cava, respectively. Through a left thoracotomy we placed polyvinyl catheters directly into the left atrium and pulmonary artery and a 3.5-French thermistor wire (Gould Statham, Statham Instruments, Inc., Hato Rey, Puerto Rico) into the pulmonary artery.

During the second operation, a right thoracotomy, we resected the systemic contributions to the caudal mediastinal lymph node and inserted a polyvinyl catheter, impregnated with heparin (TDMAC Processing, Polyscience, Inc., Warrington, PA), into the efferent duct of that node. In addition, we placed a $3 \times 3 \mathrm{~cm}$ silicone balloon (Silastic; Dow Corning Corp., Midland, MI) in the pleural space for subsequent measurement of pleural pressure. We allowed the lambs at least $3 \mathrm{~d}$ to recover from surgery before starting experiments.

Description of experiments. The average age of the six female and four male lambs at the time of study was $25 \pm 1 \mathrm{~d}$, and the average weight was $8.5 \pm 0.5 \mathrm{~kg}$. At the beginning of the study we gave each lamb sodium pentobarbital intravenously, $20 \mathrm{mg} / \mathrm{kg}$ body weight. We placed a cuffed tube in the trachea of the lambs and provided ventilation with a piston-type respirator (model 607; Harvard Apparatus Co., Inc., South Natick, MA) set at a rate of 60 breaths/min. We adjusted the tidal volume of the respirator to keep the $\mathrm{P}_{2} \mathrm{CO}_{2}$ at $\sim 40$ torr and then kept tidal volume and respirator rate constant throughout the study. The lambs breathed air for 2 to $4 \mathrm{~h}$, then 10-12\% oxygen in nitrogen for 2 to $4 \mathrm{~h}$, followed by $10-12 \%$ oxygen and $10-12 \%$ carbon dioxide in nitrogen for 2 to $4 \mathrm{~h}$. At the end of this period of hypoxia and hypercapnia, we induced a brief period of asphyxia by turning off the respirator and occluding the endotracheal tube for 1-2 min. After the period of asphyxia the lambs breathed air from the ventilator for $2-3 \mathrm{~h}$.

Throughout the study the lambs rested on a canvas sling which did not interfere with respiratory movements, and they intravenously received sodium pentobarbital, $6 \mathrm{mg} / \mathrm{kg}$ body weight, every $30 \mathrm{~min}$. They also received isotonic saline intravenously, $\sim 5 \mathrm{ml} / \mathrm{h}$ per kg body weight, an amount that caused no significant change in body weight, vascular pressures, or plasma protein concentration.

During experiments we measured vascular and pleural pressures continuously, and heart rate, respiratory rate, cardiac output and arteria $\mathrm{pH}, \mathrm{PO}_{2}$, and $\mathrm{PCO}_{2}$ at frequent intervals. In addition, we collected samples of lung lymph every $30 \mathrm{~min}$ and measured their volume to the nearest $0.01 \mathrm{ml}$; we obtained samples of aortic blood hourly. We measured pulmonary arterial, left atrial, and aortic pressures with strain gauge manometers (P23Db; Statham Instruments, Inc.) and pleural pressure with differential pressure transducer (PM131TC; Statham Instruments, Inc.). The zero reference for vascular pressures was the level of the left atrium; for measurement of pleural pressure, zero reference was at- mospheric pressure. We recorded pressures on an eight-channel amplifier recorder (7D; Grass Instruments Co., Quincy, MA) and obtained heart rate and respiratory rate from phasic recordings of aortic and pleural pressures, respectively. We measured cardiac output by indicator dilution, with either green dye (Hynson, Wescott, and Dunning, Baltimore, MD) or cold saline (11).

We calculated pulmonary vascular resistance as the difference between pulmonary arterial and left atrial pressures, divided by the cardiac output. Arterial $\mathrm{pH}, \mathrm{PO}_{2}, \mathrm{PCO}_{2}$, and inspired gas tensions were measured with a blood gas analyzer (Corning Glass Works, Medfield, MA).

In 5 of the 10 lambs, we performed tracer studies with radioiodinated albumin during the baseline period and during the recovery period after asphyxia. For this procedure, we first obtained two baseline samples of blood and lymph, after which we injected $2-3 \mu \mathrm{Ci} / \mathrm{kg}$ of ${ }^{125} \mathrm{I}$-human albumin (Mallinckrodt, Inc., St. Louis, MO) into the right atrium. We then collected samples of lymph every $15 \mathrm{~min}$ for $2-3 \mathrm{~h}$ and samples of aortic blood at the midpoint of each collection period.

Analytic methods. We spun samples of blood and lymph and measured concentrations of protein and albumin in the supernatant fluids by the biuret method (12) and by cellulose acetate electrophoresis (13) (Microzone 110; Beckman Instruments, Inc., Fullerton, CA).

For the radioactive tracer experiments we transferred $0.1 \mathrm{ml}$ of each sample of lymph and plasma into test tubes and measured the radioactivity within each sample for $1 \mathrm{~min}$ in a multichannel pulse analyzer (Searle 512; Searle Analytic, G. D. Searle and Co., Des Plaines, IL). We calculated specific activity for each sample by dividing the number of counts per minute by the concentration of albumin in the sample and plotted the specific activities as a function of time (Fig. 1). We used the method of Zilversmit et al. (14) to calculate a turnover time $(T)$ for equilibration of albumin between plasma and lymph: $T=\left(1 / \Delta S_{2}\right) \int_{11}^{12}$ $\left(S_{1}-S_{2}\right) \mathrm{d} t$, where $S_{1}$ and $S_{2}$ are specific activities of labeled albumin in plasma and lymph respectively, $t_{1}$ and $t_{2}$ are times after the injection of labeled albumin, and $\Delta S_{2}$ is the change in specific activity of labeled albumin in lymph between times $t_{1}$ and $t_{2}$ (Fig. 1). We used a desk top computer (Apple II Plus; Apple Computers Inc., Cupertino, CA), programmed for trapezoidal approximation, to integrate the areas under the two specific activity curves (R. C. Targett, A2 Devices Inc., Alameda, CA).

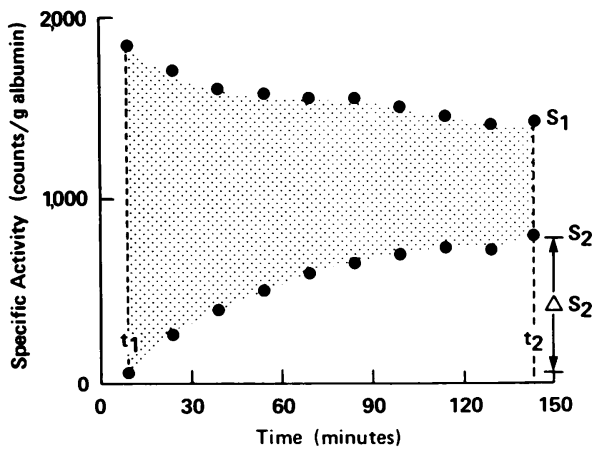

Figure 1. Plots of plasma $\left(S_{1}\right)$ and lymph $\left(S_{2}\right)$ specific activities for labeled albumin as a function of time. The turnover time $(T)$ can be calculated as $T=\left(1 / \Delta S_{2}\right) \int_{t_{1}}^{t_{2}}\left(S_{1}-S_{2}\right) \mathrm{d} t$, where $\int_{t_{1}}^{t_{2}}\left(S_{1}-S_{2}\right) \mathrm{d} t$ is the shaded area between the two curves $S_{1}$ and $S_{2}$ between times $t_{1}$ and $t_{2}$, and $\Delta S_{2}$ is the change in lymph specific activity over the same time interval. 
Postmortem studies. We killed 11 lambs to examine their lungs for evidence of edema: two lambs after $12 \mathrm{~h}$ of mechanical ventilation with air, four lambs after 4-6 $\mathrm{h}$ of ventilation with air followed by $2-3 \mathrm{~h}$ of hypoxia and hypercapnia, and five lambs after $2-3 \mathrm{~h}$ of recovery from 4-6 $\mathrm{h}$ of ventilation with air followed by $2-3 \mathrm{~h}$ of hypoxia with hypercapnia followed by severe asphyxia.

To obtain the lungs, we anesthetized each of the lambs with additional intravenous sodium pentobarbital, $10 \mathrm{mg} / \mathrm{kg}$ body weight, and resected the lungs at an inflation pressure of $25 \mathrm{~cm} \mathrm{H}_{2} \mathrm{O}$. We rapidly froze a small portion of one lobe in liquid nitrogen for subsequent examination under a microscope. We homogenized the remaining lung to measure extravascular water content by a modification (15) of the method of Pearce et al. (16).

Statistical analysis. Results in the text and tables are expressed as the mean \pm 1 SEM. We used two-factor analysis of variance and the Student-Newman-Keuls test to compare measurements made during each of the four steady state periods. We used an unpaired $t$ test corrected for multiple comparisons to compare postmortem measurements of lung water and blood content. We regarded as significant those differences that were supported by a $P$ value $<0.05$ (17).

\section{Results}

Hypoxia alone. During anesthesia and constant ventilation, alveolar hypoxia had no significant effect on arterial $\mathrm{pH}, \mathrm{PCO}_{2}$, heart rate, systemic arterial pressure, systemic venous pressure, or pleural pressure (Table I).

Mean pulmonary arterial pressure increased on the average by $60 \%$; cardiac output and left atrial pressure were unaffected by hypoxia. As pulmonary vascular resistance increased by $60 \%$ during hypoxia, average lung lymph flow increased by $74 \%$; the concentration of protein in lymph decreased without any change in plasma protein concentration (Table II, Fig. 2). The ratio of albumin to globulin in lymph relative to the ratio in plasma did not change.

Hypoxia and hypercapnia. The addition of $10-12 \% \mathrm{CO}_{2}$ to the inspired gas had no effect on heart rate, mean aortic or systemic venous pressure, or pleural pressure (Table I). Mean pulmonary arterial pressure increased $22 \%$ and cardiac output increased $13 \%$. Left atrial pressure and calculated pulmonary vascular resistance did not change. Lung lymph flow increased by $33 \%$, and lymph protein concentration decreased (Table II, Fig. 2). The ratio of albumin to globulin in lymph relative to that in plasma remained unchanged.

Asphyxia. The duration of asphyxia was 1 to $2 \mathrm{~min}$ in all 10 lambs. Arterial blood obtained at the end of this period had a mean $\mathrm{pH} 6.88 \pm 0.02, \mathrm{PO}_{2} 18 \pm 5$ and $\mathrm{PCO}_{2} 104 \pm 9$ torr. Five the 10 lambs required resuscitation with external cardiac massage and injection of bicarbonate and epinephrine after asphyxia.

Recovery from asphyxia. We studied the lambs for at least $2 \mathrm{~h}$ after the acute asphyxial insult. During recovery, arterial $\mathrm{PO}_{2}$ and $\mathrm{PCO}_{2}$ returned to values similar to those obtained during the control period, but the animals remained acidemic. Mean aortic pressure was lower after asphyxia than during any of the preceding periods. Heart rate and mean pleural pressure were unchanged (Table I).

During asphyxia, pulmonary arterial and left atrial pressures both increased. During recovery from asphyxia, pulmonary arterial and left atrial pressures, cardiac output, and lung lymph flow all rapidly returned to control values (Table II, Fig. 2). Although lymph and plasma protein concentrations were less than they were during the baseline period, neither the lymph protein concentration relative to the plasma protein concentration nor the ratio of albumin to globulin in lymph relative to the same ratio in plasma was significantly different from values obtained during the baseline period. The turnover time for ${ }^{125} \mathrm{I}$-albumin after asphyxia was not significantly different from that measured during the baseline period (185 \pm 16 vs. $179 \pm 12 \mathrm{~min})$.

Postmortem measurements. Both lung blood and extravascular lung water content decreased during asphyxia and remained decreased throughout the $3-h$ recovery period (Table III). A comparable period of mechanical ventilation with air had no effect on either lung water or lung blood content. We examined sections of frozen lung by light microscopy and found that they were well inflated, with no evidence of edema or hemorrhage.

\section{Discussion}

We previously showed that alveolar hypoxia increases pulmonary arterial pressure and lung lymph flow and decreases the con-

Table I. Cardiorespiratory Variables in 10 Anesthetized Lambs Before, During, and After Progressive Asphyxia

\begin{tabular}{|c|c|c|c|c|c|c|}
\hline Inspired gas & $\mathrm{pH}$ & $\mathrm{Pa}_{\mathrm{a}} \mathrm{CO}_{2}$ & $\mathrm{P}_{2} \mathrm{O}_{2}$ & $\begin{array}{l}\text { Heart } \\
\text { rate }\end{array}$ & $\begin{array}{l}\text { Mean aortic } \\
\text { pressure }\end{array}$ & $\begin{array}{l}\text { Mean pleural } \\
\text { pressure }\end{array}$ \\
\hline & & torr & torr & & torr & torr \\
\hline Air (baseline) & $7.43 \pm 0.01$ & $39 \pm 1$ & $91 \pm 3$ & $210 \pm 11$ & $100 \pm 2$ & $-1 \pm 0.5$ \\
\hline $10-12 \% \mathrm{O}_{2}$ & $7.41 \pm 0.02$ & $38 \pm 1$ & $36 \pm 1 *$ & $220 \pm 12$ & $92 \pm 3$ & $-1 \pm 0.5$ \\
\hline \multicolumn{7}{|l|}{$10-12 \% \mathrm{O}_{2}$} \\
\hline$+10-12 \% \mathrm{CO}_{2}$ & $7.02 \pm 0.02 * t$ & $83 \pm 2^{* \dagger}$ & $40 \pm 2^{*}$ & $220 \pm 10$ & $92 \pm 6$ & $-2 \pm 0.5$ \\
\hline Air (recovery) & $7.27 \pm 0.04^{*}$ & $37 \pm 2$ & $87 \pm 2$ & $195 \pm 10$ & $80 \pm 8 *$ & $-1 \pm 0.5$ \\
\hline
\end{tabular}

All data are mean \pm SEM. * Different from baseline (air breathing), $P<0.05$. † Different from $10-12 \% O_{2}, P<0.05$ 
Table II. Lung Fluid Filtration in 10 Anesthetized Lambs Before, During, and After Progressive Asphyxia

\begin{tabular}{|c|c|c|c|c|c|c|c|c|c|c|}
\hline \multirow[b]{2}{*}{ Inspired gas } & \multicolumn{2}{|c|}{ Vascular pressures } & \multirow[b]{2}{*}{$\begin{array}{l}\text { Cardiac } \\
\text { output }\end{array}$} & \multirow[b]{2}{*}{$\begin{array}{l}\text { Lung lymph } \\
\text { flow }\end{array}$} & \multicolumn{3}{|c|}{ Protein concentration } & \multicolumn{3}{|c|}{ Albumin/globulin } \\
\hline & $\begin{array}{l}\text { Pulmonary } \\
\text { artery }\end{array}$ & $\begin{array}{l}\text { Left } \\
\text { atrium }\end{array}$ & & & Lymph & Plasma & $\begin{array}{l}\text { Lymph/ } \\
\text { Plasma }\end{array}$ & Lymph & Plasma & $\begin{array}{l}\text { Lymph/ } \\
\text { Plasma }\end{array}$ \\
\hline & torr & torr & $\begin{array}{l}\mathrm{ml} / \mathrm{kg} \mathrm{per} \\
\mathrm{min}\end{array}$ & $m l / h$ & $g / d l$ & $g / d l$ & & & & \\
\hline Air (baseline) & $20 \pm 1$ & $4 \pm 1$ & $242 \pm 16$ & $2.36 \pm 0.40$ & $3.47 \pm 0.13$ & $5.45 \pm 0.08$ & $0.64 \pm 0.02$ & $1.54 \pm 0.10$ & $0.78 \pm 0.03$ & $1.95 \pm 0.10$ \\
\hline $10-12 \% \mathrm{O}_{2}$ & $32 \pm 2 *$ & $4 \pm 1$ & $264 \pm 27$ & $4.10 \pm 0.40^{*}$ & $2.83 \pm 0.15^{*}$ & $5.30 \pm 0.10$ & $0.53 \pm 0.02^{*}$ & $1.66 \pm 0.15$ & $0.76 \pm 0.02$ & $2.19 \pm 0.18$ \\
\hline \multicolumn{11}{|l|}{$10-12 \% \mathrm{O}_{2}$} \\
\hline$+10-12 \% \mathrm{CO}_{2}$ & $39 \pm 2 * \dagger$ & $5 \pm 1$ & $300 \pm 30^{*}+$ & $5.47 \pm 0.56^{*} \dagger$ & $2.41 \pm 0.13^{*} \dagger$ & $5.31 \pm 0.13$ & $0.45 \pm 0.02^{*} \dagger$ & $1.53 \pm 0.13$ & $0.81 \pm 0.04$ & $1.88 \pm 0.10$ \\
\hline Air (recovery) & $20 \pm 1$ & $4 \pm 1$ & $223 \pm 18$ & $2.18 \pm 0.38$ & $3.21 \pm 0.14^{*}$ & $5.18 \pm 0.14^{*}$ & $0.62 \pm 0.02$ & $1.37 \pm 0.11$ & $0.80 \pm 0.03$ & $1.69 \pm 0.11$ \\
\hline
\end{tabular}

All data, mean \pm SEM. * Different from baseline (air breathing), $P<0.05 . \quad \dagger$ Different from $10-12 \% \mathrm{O}_{2}, P<0.05$.

centration of protein in lymph of newborn lambs $(4,18)$. In the experiments reported here we found that sustained hypoxia and hypercapnia followed by severe asphyxia caused a further increase in lung lymph flow and decrease in lymph protein

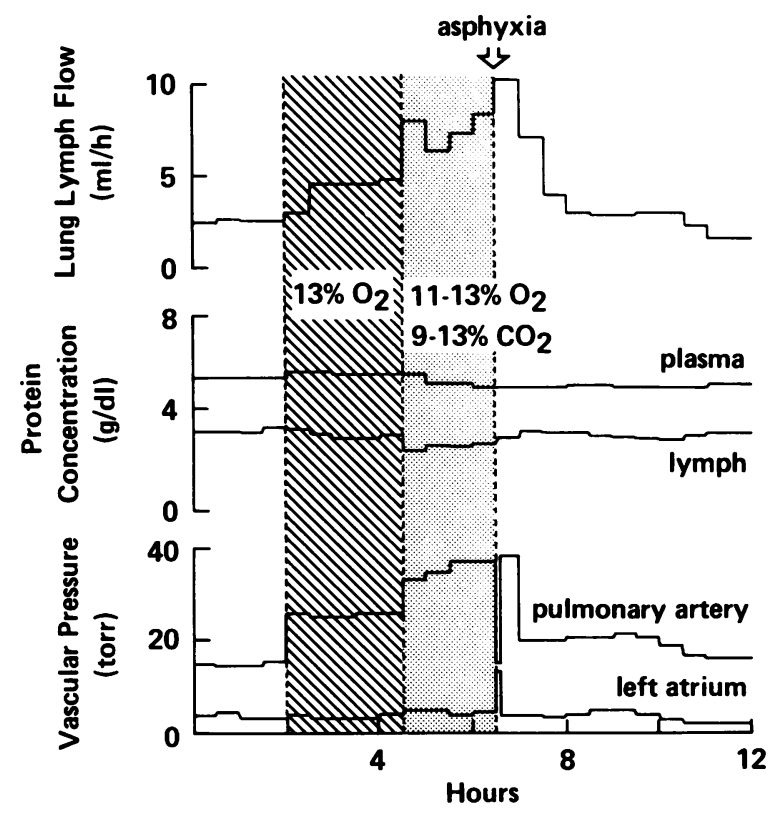

Figure 2. Time course of one experiment. Hypoxia abruptly increased pulmonary arterial pressure and lung lymph flow and decreased lymph protein concentration, without affecting left atrial pressure or plasma protein concentration. Addition of $\mathrm{CO}_{2}$ to the inspired gas further increased pulmonary arterial pressure and lung lymph flow and decreased lymph protein concentration. After the episode of acute severe asphyxia, vascular pressures, lung lymph flow, and lymph protein concentration all rapidly returned to baseline values. concentration, followed by a rapid return to control values during recovery from asphyxia. If we assume that the concentration of protein in lymph approximates that in the pulmonary interstitium $(19,20)$, then measurement of lung lymph flow and of the concentration of protein in lymph provides a sensitive index of net transvascular movement of fluid and protein in the lung $(21,22)$. Our results suggest, therefore, that alveolar hypoxia increases the net transvascular filtration of fluid in the lungs of lambs by increasing filtration pressure in the pulmonary microcirculation. The further increase in pulmonary arterial pressure and lung lymph flow and decrease in the concentration of protein in lymph during hypoxia with hypercapnia and asphyxia suggests that filtration pressure increased even further during the imposed respiratory acidosis, probably as a result of the associated increase in pulmonary blood flow. During combined hypoxia and hypercapnia there was no further increase in pulmonary vascular resistance. These results are consistent with those recently reported by Mitzner and Sylvester (23), who showed that alveolar hypoxia accentuated increases in lung fluid filtration associated with increased perfusion of isolated pig lungs.

The decrease in lymph protein concentration during combined hypoxia and hypercapnia indicates that the permeability of the pulmonary microcirculation to protein was unaffected by persistent respiratory acidosis. To evaluate further this hypothesis, we plotted the lymph-to-plasma protein ratio as a function of rate of lung lymph flow for all 10 lambs (Fig. 3). We compared the results with those from two other sets of experiments also done in our laboratory: in one set, we increased lung lymph flow by inflating a balloon in the left atrium of seven lambs, so that filtration pressure in the pulmonary microcirculation increased by $\sim 10$ torr (24); in the second set, lymph flow was increased by putting the lambs in $100 \%$ oxygen for 3-5 d (25). During hypoxia with hypercapnia, as lymph flow increased the lymph/plasma protein ratio decreased, just as it did when filtration pressure was increased by inflation of a bal- 


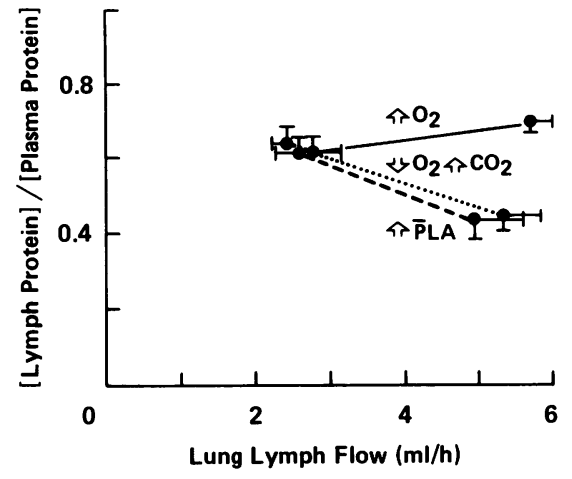

Figure 3. Test for differences in lung microvascular permeability to protein in lambs. When elevated lung microvascular pressure ( $\uparrow$ Pla: inflated left atrial balloon) increases lung lymph flow, the lymph/ plasma protein ratio decreases. When continuous oxygen breathing $\left(\mathrm{TO}_{2}\right)$ for $5 \mathrm{~d}$ causes a permeability change, lymph flow also increases, but the lymph/plasma protein ratio increases. During hypoxia with hypercapnia $\left(\mathrm{lO}_{2}, \uparrow \mathrm{CO}_{2}\right)$, as lymph flow increases, the lymph/plasma protein ratio decreases, just as it does when filtration pressure increases.

loon in the left atrium. The response was clearly different from that which occurred when microvascular permeability to protein was increased by sustained hyperoxia. In addition, during hypoxia with hypercapnia, the ratio of albumin/globulin in lymph relative to that in plasma did not decrease, suggesting that the sieving properties of the microvascular membrane did not change.

We conclude that hypoxia with hypercapnia increases lung lymph flow by increasing filtration pressure in the pulmonary microcirculation. This probably occurs secondary to the increased pulmonary blood flow observed during hypoxia with acidemia.

The brief period of total asphyxia was severe, as reflected by the arterial blood gas tensions and the subsequent need for resuscitation in five of the lambs. Despite this severe insult, recovery was associated with a rapid return to baseline of pulmonary arterial and left atrial pressures, lung lymph flow, and lymph protein concentration. These findings indicate that asphyxia did not injure the pulmonary microcirculation.

We further investigated the possibility that asphyxia had damaged the capillary endothelium of the lung by measuring the turnover time $(T)$ for radioiodinated albumin during the baseline period in air and during recovery from asphyxia. We found no difference. Our results are very similar to those obtained by Adamson and co-workers (3), who found no change in pulmonary capillary permeability to protein in fetal lambs subjected to brief asphyxia by umbilical cord occlusion. They concluded, as we did, that an increase in lung lymph flow during asphyxia was the result of an increase in lung microvascular pressure.

Our results are different from those obtained by O'Brodovich and co-workers (8), who studied the effects of hypoxia and hy- percapnia on lung fluid balance in conscious yearling sheep. In their experiments, lung lymph flow increased and the concentration of protein in lymph decreased during combined hypoxia and hypercapnia. The decrease in lymph protein concentration was less than that observed when they increased lymph flow by inflating a balloon in the left atrium of the sheep. They attributed the change to lung microvascular injury. To support this view, they showed IgM flux was greater than IgG flux during hypoxia with acidemia than it was during hypoxia alone or during left atrial pressure elevation.

There are several possible reasons for the apparent discrepancy between their results and ours. First, their studies were considerably shorter than ours were. The average duration of hypoxia and hypercapnia was only $1 \mathrm{~h}$; it is possible that they did not wait long enough to observe the "washdown" of the lymph protein concentration that occurs when lung microvascular pressure increases. In newborn lambs stressed by alveolar hypoxia or hypercapnia, the protein concentration in lung lymph often takes several hours to reach a steady state $(18,26)$. When we prolonged hypoxia and hypercapnia for $2-3 \mathrm{~h}$ in these experiments, the increase in lung lymph flow and the decrease in lymph protein concentration paralleled the changes observed by O'Brodovich and co-workers when they raised left atrial pressure in their sheep. Second, our lambs were anesthetized and mechanically ventilated, whereas the animals studied by O'Brodovich et al. were conscious and breathed spontaneously. It is possible that anesthesia may inhibit lung endothelial injury, but other studies indicate that this is unlikely (27). In previous experiments we showed that neither anesthesia nor mechanical ventilation inhibits the increase in lymph flow that occurs when lambs become hypoxic (18). Third, it may have been incorrect for O'Brodovich et al. to interpret the increase in lymph IgM concentration as evidence of increased lung vascular permeability: Gorin and Gould (28) showed that both IgG and IgM enter the lymph from the caudal mediastinal lymph node of the sheep. Consequently, increases of lymph immunoglobulin concentrations may simply reflect increased release from lymphatic tissue rather than increased capillary permeability.

The decrease in lung water during the control period and after recovery from asphyxia was unexpected and was not simply the result of prolonged mechanical ventilation (Table III). One possible explanation is that hypoxia, in particular hypoxia with hypercapnia, stimulated contraction of lung lymphatics and caused them to pump water out of the interstitium of the lung, thereby increasing lung lymph flow and decreasing lung water content. If we assume, however, that we collected two thirds of total lung lymph flow (29), the observed increase in lung lymph flow was more than could be accounted for by the decrease in lung water. Therefore, at least some of the increase in lymph flow must come from a circulating source, such as plasma. Furthermore, the decrease in lung water content observed during recovery from asphyxia could not have resulted from lymphatic drainage because lymph flow returned to the baseline level after asphyxia. 
Table III. Postmortem Measurements of Extravascular Lung Water and Lung Blood Content

\begin{tabular}{|c|c|c|c|c|}
\hline Ventilation before death & Inspired gas & Number & $\begin{array}{l}\text { Extravascular } \\
\text { lung water }\end{array}$ & Lung blood \\
\hline & & & \multicolumn{2}{|c|}{$g / g$ dry lung excluding blood } \\
\hline Spontaneous, unassisted & Air & 10 & $4.72 \pm 0.14$ & $2.22 \pm 0.25$ \\
\hline Mechanical ventilation* & Air & 2 & $4.80 \pm 0.06$ & $2.24 \pm 0.80$ \\
\hline Mechanical ventilation $\ddagger$ & $10-12 \% \mathrm{O}_{2}+10-12 \% \mathrm{CO}_{2}$ & 4 & $4.27 \pm 0.12 \pi$ & $1.50 \pm 0.18 \pi$ \\
\hline Mechanical ventilation§ & Air postasphyxia & 5 & $4.00 \pm 0.15 \pi$ & $1.47 \pm 0.219$ \\
\hline
\end{tabular}

All data, mean \pm SEM. ${ }^{*}$ Ventilated in air for $12 \mathrm{~h}$, then killed. $¥$ Ventilated in air for 4-6 h, then with $10-12 \% \mathrm{O}_{2}$ and $10-12 \% \mathrm{CO}_{2}$ for $4 \mathrm{~h}$, then killed. § Ventilated in air for 4-6 h, then with $10-12 \% \mathrm{O}_{2}$ and $10-12 \% \mathrm{CO}_{2}$ for $4 \mathrm{~h}$, asphyxiated, recovered in air for 2-3 h, then killed. I Different from spontaneously breathing controls, $P<0.05$.

An alternative explanation for the postasphyxial reduction in lung water is that pulmonary vasoconstriction during hypoxia and hypoxia with hypercapnia may have nonuniform effects on fluid exchange vessels in the lung microcirculation. In some parts of the lung, flow might stop altogether, thereby reducing microvascular surface area for fluid filtration, while in other channels, intense arteriolar constriction might reduce filtration pressure enough to facilitate reabsorption of fluid. In support of these ideas, we observed a reduction in lung blood volume in lambs after asphyxia. In perfused vessels, however, filtration pressure must have been great enough to increase lymph flow and decrease the concentration of protein in lymph.

Barie et al. (30) found that decreased lung perfusion reduces transvascular fluid filtration and increases interstitial protein concentration. Pang et al. (31) demonstrated that the closure of vessels in areas of atelectasis decreases the rate of transvascular fluid filtration. Nonuniform intense pulmonary vasoconstriction could have a similar effect. In the remaining open channels, although filtration pressure would be high, lung lymphatics would keep interstitial water content normal over a wide range of filtration pressures (15). Consequently, overall lung water content might be normal or even reduced. During the period of hypoxia and hypercapnia the protein concentration in the interstitial fluid surrounding perfused microvessels would be low because of the high filtration pressure. During recovery from asphyxia the microvascular pressure would decrease throughout the lung, whereas plasma protein osmotic pressure would remain unchanged. Net filtration pressure in vessels with a low concentration of protein in the surrounding interstitium would be low because the transmural difference in protein osmotic pressure would be large. These conditions would favor net reabsorption of fluid and a further reduction in extravascular lung water.

Several investigators have demonstrated that hypoxia alters the pattern of pulmonary perfusion. Haab et al. (32) analyzed alveolar-arterial gradients for nitrogen and found that hypoxia exaggerates ventilation perfusion imbalances. Viswanathan et al. (33) performed perfusion lung scans on adults who had experienced high altitude pulmonary edema and found a patchy redistribution of perfusion during hypoxia. Dawson and coworkers $(34,35)$ found increases in upper lung perfusion in human subjects during alveolar hypoxia, and Dugard and Naimark (36) found that during hypoxia blood flowed preferentially toward the top of the lung in the upright dog. Recently, Capen et al. (37) confirmed that observation using in vivo microscopy and radioactive microspheres in dogs during alveolar hypoxia.

Other investigators have studied the effects that such a redistribution of perfusion would have on filtration pressure in the microcirculation of the lung. Hyman (38) studied how progressive segmental closure of lung vessels influenced pressureflow relationships in pulmonary arteries and veins of dogs. He perfused selected segments of the lungs at varying flow rates and found that as segment size decreased, pressure in both pulmonary arteries and veins increased; i.e., filtration pressure increased. In similar experiments, Hultgren (39) simulated blood flow redistribution by perfusing lobes of dog lungs at successively higher flow rates until pulmonary edema occurred. Landolt and associates (40) also found that pulmonary edema developed in sheep when three-quarters of their lung tissue was removed and cardiac output was held constant by blood transfusion.

We previously showed that blood flow per unit lung mass is greater in newborn lambs than it is in adult sheep (5). In this respect, the newborn lung is analogous to the partially resected adult lung, in which increased blood flow enhances fluid filtration and lymph flow in those parts of the microcirculation that are perfused. In hypoperfused areas of the lung, an increased transmural protein osmotic pressure difference would facilitate reabsorption of fluid. These conditions probably prevailed in our lambs after asphyxia, when their lung vascular pressure and interstitial protein osmotic pressure were low, possibly accounting for the reduced lung lymph flow and lung water content that we observed during the recovery phase of our experiments.

\section{Acknowledgments}

The authors thank R. B. Goldberg and T. M. Chou for their technical assistance and $\mathbf{M}$. Rich and $M$. Biagini for typing the manuscript.

The work presented in this paper was supported in part by the National Heart, Lung, and Blood Institute (NHLBI) Pulmonary Specialized Center of Research grant HL 19185, and by U. S. Public Health Service Program Project grants HL/HD 24056 and HL 25816. 
T. N. Hansen and T. A. Hazinski were trainees supported by NHLBI Pulmonary Faculty Training grant HL 07159.

\section{References}

1. Courtice, F. C., and P. I. Korner. 1952. The effect of anoxia on pulmonary oedema produced by massive intravenous infusions. Aust. J. Exp. Biol. Med. Sci. 30:511-526.

2. Lance, J. S., and H. Latta. 1963. Hypoxia, atelectasis and pulmonary edema. Arch. Pathol. 75:373-377.

3. Adamson, T. M., R. D. H. Boyd, J. R. Hill, I. C. S. Normand, E. O. R. Reynolds, and L. B. Strang. 1970. Effect of asphyxia due to umbilical cord occlusion in the foetal lamb on leakage of liquid from the circulation and on permeability of lung capillaries to albumin. $J$. Physiol. 207:493-505.

4. Bressack, M. A., and R. D. Bland. 1980. Alveolar hypoxia increases lung fluid filtration in unanesthetized lambs. Circ. Res. 46:111-116.

5. Bland, R. D., M. A. Bressack, C. M. Haberkern, and T. N. Hansen. 1980. Lung fluid balance in hypoxic, awake newborn lambs and mature sheep. Biol. Neonate. 38:221-228.

6. Warren, M. F., and C. K. Drinker. 1942. The flow of lymph from the lungs of the dog. Am. J. Physiol. 136:207-221.

7. Boonyaprakob, U., P. M. Taylor, D. W. Watson, B. Waterman, and E. Lopata. 1969. Hypoxia and protein clearance from the pulmonary vascular beds of adult dogs and pups. Am. J. Physiol. 216:1013-1019.

8. O'Brodovich, H. M., S. A. Stalcup, L. M. Pang, J. S. Lipset, and R. B. Mellins. 1981. Bradykinin production and increased pulmonary endothelial permeability during acute respiratory failure in unanesthetized sheep. J. Clin. Invest. 67:514-522.

9. Staub, N. C., R. D. Bland, K. L. Brigham, R. H. Demling, A. J. Erdmann, and W. C. Woolverton. 1975. Preparation of chronic lung lymph fistulas in sheep. J. Surg. Res. 19:315-320.

10. Bland, R. D., and D. D. McMillan. 1977. Lung fluid dynamics in awake newborn lambs. J. Clin. Invest. 60:1107-1115.

11. Rudolph, A. M. 1974. Congenital Diseases of the Heart: ClinicalPhysiological Considerations in Diagnosis and Management. Year Book Medical Publishers, Inc., Chicago. 139-149.

12. Gornall, A. G., G. J. Bardawill, and M. M. David. 1949. Determination of serum proteins by means of the biuret reaction. J. Biol. Chem. 177:751-766.

13. Wieme, R. J. 1965. Agar Electrophoresis. Elsevier/North Holland, Amsterdam. 1-352.

14. Zilversmit, D. B., C. Entenman, and M. C. Fishler. 1943. On the calculation of "turnover time" and "turnover rate" from experiments involving the use of labeling agents. J. Gen. Physiol. 26:325-331.

15. Erdmann, A. J., III, T. R. Vaughan, Jr., K. L. Brigham, W. C. Woolverton, and N. C. Staub. 1975. Effect of increased vascular pressure on lung fluid balance in unanesthetized sheep. Circ. Res. 37:271-284.

16. Pearce, M. L., J. Yamashita, and J. Beazell. 1965. Measurement of pulmonary edema. Circ. Res. 16:482-488.

17. Snedecor, G. W., and W. G. Cochran. 1972. Statistical Methods. Iowa State University Press, Ames, Iowa. 91-119.

18. Hansen, T. N., T. A. Hazinski, and R. D. Bland. 1984. Lung fluid balance in hypoxic lambs. Pediatr. Res. 18:434-440.

19. Nicolaysen, G., A. Nicolaysen, and N. C. Staub. 1975. A quantitative radioautographic comparison of albumin concentration in different sized lymph vessels in normal mouse lungs. Microvasc. Res. 10:138-152.
20. Vreim, C. E., P. D. Snashall, R. H. Demling, and N. C. Staub. 1976. Lung lymph and free interstitial fluid protein composition in sheep with edema. Am. J. Physiol. 230:1650-1653.

21. Staub, N. C. 1974. Pulmonary edema. Physiol. Rev. 54:678811.

22. Brigham, K. L., W. C. Woolverton, L. H. Blake, and N. C. Staub. 1975. Increased sheep lung vascular permeability caused by pseudomonas bacteremia. J. Clin. Invest. 54:792-804.

23. Mitzner, W., and J. T. Sylvester. 1981. Hypoxic vasoconstriction and fluid filtration in pig lungs. J. Appl. Physiol. 51:1065-1071.

24. Bland, R. D., T. N. Hansen, T. A. Hazinski, C. M. Haberkern, and M. A. Bressack. 1982. Studies on lung fluid balance in newborn lambs. Ann. NY Acad Sci. 384:126-145.

25. Bressack, M. A., D. D. McMillan, and R. D. Bland. 1979. Pulmonary oxygen toxicity: increased microvascular permeability to protein in unanesthetized lambs. Lymphology. 12:133-139.

26. Haberkern, C. M., and R. D. Bland. 1981. Effects of hypercapnia on net filtration of fluid in the lungs of awake newborn lambs. J. Appl. Physiol. 51:423-427.

27. Binder, A. S., W. Kaegler, A. Perel, M. R. Flick, and N. C. Staub. 1980. Effect of platelet depletion on lung vascular permeability after microemboli in sheep. J. Appl. Physiol. 48:414-420.

28. Gorin, A. B., and J. Gould. 1979. Immunoglobulin synthesis in the lungs and caudal mediastinal lymph node of sheep. J. Immunol. 123:1339-1342.

29. Humphreys, P. W., I. C. S. Normand, E. O. R. Reynolds, and L. B. Strang. 1967. Pulmonary lymph flow and the uptake of liquid from the lungs of the lamb at the start of breathing. J. Physiol. 193:129.

30. Barie, P. S., T. S. Hakim, and A. B. Malik. 1981. Effect of pulmonary artery occlusion and reperfusion on extravascular fluid accumulation. J. Appl. Physiol. 50:102-106.

31. Pang, L. M., F. Rodriguez-Martinez, S. A. Stalcup, and R. B. Mellins. 1978. Effect of hyperinflation and atelectasis on fluid accumulation in the puppy lung. J. Appl. Physiol. 45:284-288.

32. Haab, P., D. R. Held, H. Ernst, and L. E. Farhi. 1969. Ventilationperfusion relationships during high-altitude adaptation. J. Appl. Physiol. 26:77-81.

33. Viswanathan, R., S. Subraminian, and T. G. Radha. 1979. Effect of hypoxia on regional lung perfusion by scanning. Respiration. 37:142147.

34. Dawson, A. 1969. Regional pulmonary blood flow in sitting and supine man during and after acute hypoxia. J. Clin. Invest. 48:301-310.

35. Dawson, A. 1972. Regional lung function during early acclimatization to 3,100 m altitude. J. Appl. Physiol. 33:218-223.

36. Dugard, A., and A. Naimark. 1967. Effect of hypoxia on distribution of pulmonary blood flow in awake standing dogs. J. Appl. Physiol. 23:663-671.

37. Capen, R. L., and W. W. Wagner, Jr. 1982. Intrapulmonary blood flow redistribution during hypoxia increases gas exchange surface area. J. Appl. Physiol. 52:1575-1580.

38. Hyman, A. L. 1969. Effects of large increases in pulmonary blood flow on pulmonary venous pressure. J. Appl. Physiol. 27:179185.

39. Hultgren, H. N. 1978. High altitude pulmonary edema. In Lung, Water, and Solute Exchange. N. C. Staub, editor. Marcel Dekker, Inc., New York. 437-469.

40. Landolt, C. C., M. Matthay, and N. C. Staub. 1980. Lung resection, increased blood flow and pressure in sheep: failure to detect pore stretching or high linear flow injury. Microvasc. Res. 20:117. (Abstr.) 